\title{
Pathophysiology and Biomarkers in Acute Ischemic Stroke - A Review
}

\author{
Yiwang Guo, Pengyue Li, Qingli Guo, Kexin Shang, Dan Yan, Shouying Du* \\ and Yang Lu* \\ Department of TCM Pharmaceutics, School of Chinese Pharmacy, Beijing University of Chinese Medicine, Beijing 100102, \\ China.
}

*For correspondence: Email: dushouying@263.net, landocean28@163.com; Tel: +86-10-8473-8615; Fax: +86-108473-8611

\begin{abstract}
Stroke is one of the major causes of death and disability, including ischemic stroke, which accounts for $85-87 \%$ of cases. Currently, there are few treatment options available for minimizing tissue death following a stroke. Emerging data suggest that biomarkers may help improve current clinical outcome of stroke. As such, there is a pressing need to understand the pathophysiology and to explore effective biomarkers following an ischemic brain event. The pathophysiology of ischemic stroke is complex, and majorly involves excitotoxicity, oxidative stress, inflammation, blood-brain barrier dysfunction, apoptosis, etc. Several of the biomarkers are related to these pathophysiologic mechanisms and they may have applications in stroke prediction, diagnosis, assessment, prognosis or treatment. In this review, we summarized the pathophysiology of ischemic stroke and some related biomarkers are examined.
\end{abstract}

Keywords: Ischemic stroke, Pathophysiology, Biomarker, Clinical outcomes

Tropical Journal of Pharmaceutical Research is indexed by Science Citation Index (SciSearch), Scopus, International Pharmaceutical Abstract, Chemical Abstracts, Embase, Index Copernicus, EBSCO, African Index Medicus, JournalSeek, Journal Citation Reports/Science Edition, Directory of Open Access Journals (DOAJ), African Journal Online, Bioline International, Open-J-Gate and Pharmacy Abstracts

\section{INTRODUCTION}

Stroke is a serious neurological disease and a leading cause of disability worldwide [1]. Ischemic strokes constitute $85-87 \%$ of all cases. Hemorrhagic stroke includes spontaneous intracerebral hemorrhage and subarachnoid hemorrhage, and account for the remainder of cases [2].For its enormous clinical, social and economic implications, it is urgent to understand the mechanisms and thereby guiding the diagnosis and therapy of stroke. Though neuro-imaging examinations such as computed tomography (CT) and magnetic resonance imaging (MRI) are excellent in the management of stroke patients, biomarkers to support a clinical diagnosis of stroke, identify patients at risk of disease, and guide treatment and prognosis would be valuable [3]. To date, many ischemic stroke candidate biomarkers have been identified, but none are currently used in clinical practice, so further studies and researches are demanded. The primary objectives of this review are to summarize: $(A)$ the pathophysiology of stroke and (B) current understanding of biomarkers in stroke.

\section{PATHOPHYSIOLOGY OF ISCHEMIC STROKE}

Ischemic cerebrovascular disease is mainly caused by thrombosis, embolism and focal hypoperfusion, all of which can lead to a reduction or an interruption in cerebral blood 
flow (CBF) that affect neurological function. As the brain receives $20 \%$ of the cardiac output at rest [4], it is exquisitely sensitive to ischemia, such that even brief ischemic periods to neurons can trigger a complex sequence of events that may result in permanent cerebral damage.

Normally, the average CBF in an adult is approximately $50-55 \mathrm{ml} / 100 \mathrm{~g} / \mathrm{min}$ [5]. During brain ischemia, critically reduced $\mathrm{CBF}$ causes an inadequate delivery of oxygen and glucose, triggering the evolution of stroke pathophysiology process. Generally, pathophysiology of ischemic stroke can be said to be in two stages [5,6]: at a CBF of approximately $14 \pm 2 \mathrm{ml} / 100 \mathrm{~g} / \mathrm{min}$, the electroencephalogram becomes isoelectric or evoked responses become abnormal, it's a region of functionally impaired but structurally intact tissue, called ischemic penumbra and brain damage here is reversible; when $\mathrm{CBF}$ is reduced to approximately $6 \mathrm{ml} / 100 \mathrm{~g} / \mathrm{min}$, the brain damage becomes irreversible and results in brain infarction, which is called ischemic core. In this regard, salvaging of ischemic penumbra is the clinical target for acute stroke therapy.

The pathophysiology of stroke is extremely complex and involves numerous processes, including: energy failure, excitotoxicity, oxidative stress, disruption of the blood-brain barrier (BBB), inflammation, necrosis or apoptosis etc.

\section{Excitotoxicity}

Excitotoxicity refers to a sequence of events induced by excessive accumulation of excitatory amino acids, leading to toxic increases in intracellular calcium [7]. As a second messenger, $\mathrm{Ca}^{2+}$ activates multiple signaling pathways, which eventually leads to necrosis or apoptosis. Soon after reduction or termination of $\mathrm{CBF}$, energy-dependent $\mathrm{Na}^{+}-\mathrm{K}^{+}$-ATP enzyme is inhibited due to reduced ATP production, resulting in turbulence of numerous ions, including $\mathrm{Na}^{+}, \mathrm{Cl}^{-}, \mathrm{Ca}^{2+}$. These ions can also be interrupted by the overstimulation of 1-amino-3hydroxy-5-methyl-4-isoxazole propionic acid (AMPA), kainate and $\mathrm{N}$-methyl-d-aspartic acid (NMDA)-type glutamate receptors, all of which are receptors of glutamate, a major excitatory neurotransmitter in the brain. Then these cells become depolarized, which in turn cause more $\mathrm{Ca}^{2+}$ influx and more glutamate release. Influxing of numerous ions may result in acute swelling of cells and additionally, $\mathrm{Ca}^{2+}$ triggers a series of events by $\mathrm{Ca}^{2+}$-dependent enemy and ultimately causing cell death.

\section{Oxidative stress}

"Oxidative stress" was first propounded by Professor Sohal in 1990. It occurs when there is an imbalance between production of free radicals and endogenous scavenging capacity of cellular antioxidants. Increasing evidence suggests that reactive oxygen and nitrogen molecules are closely linked to tissue injury during acute ischemic stroke [8,9]. Free radicals include superoxide anion $\left(\mathrm{O}_{2}^{-}\right)$, hydroxyl radical $(\mathrm{OH} \cdot)$, hydrogen peroxide $\left(\mathrm{H}_{2} \mathrm{O}_{2}\right)$, nitric oxide (NO) and so on. Among which, $\mathrm{O}_{2}^{-}$is generated earliest, while $\mathrm{OH} \cdot$ is the most toxic.

During ischemic stroke, superoxide anion is the primarily generated radical through several ways, including mitochondrial electron transport process [10], xanthine oxidase (XO) system which is thought to be a major source for the generation of oxygen free radicals in ischemia and reperfusion [11,12], and metabolism of arachidonic acid (AA) through the cyclooxygenase $(\mathrm{COX})$ pathways. $\mathrm{H}_{2} \mathrm{O}_{2}$ is formed from superoxide anion and it is the source of $\mathrm{OH} \cdot$. NO is generated from L-arginine by nitric oxide synthases (NOS) which are $\mathrm{Ca}^{2+}$-dependent. NO is very short lived and what's more, it can react with superoxide anion to produce peroxynitrite (ONOO-), another highly toxic oxygen species [13]. On the other hand, antioxidants like superoxide dismutase (SOD), glutathione peroxidase (GPX) and catalase (CAT) degrade superoxide anion into $\mathrm{H}_{2} \mathrm{O}_{2}$, additionally transfer $\mathrm{H}_{2} \mathrm{O}_{2}$ into $\mathrm{H}_{2} \mathrm{O}$. Despite these defenses, the brain is vulnerable to oxidative stress resulting from ischemia and reperfusion.

Oxidative stress is a significant injury during cerebral ischemia, these free radicals can attack DNA, proteins and lipids [14], increase $\mathrm{Ca}^{2+}$, disrupt mitochondrial integrity from which Cytochrome $\mathrm{C}$ is always released to trigger apoptosis, cause varying degrees of damage, ultimately result to cell death.

\section{Inflammation}

Several cell types contribute to post-ischemic inflammation, including endothelial cells, astrocytes, microglia and neurons [15]. The key elements in an inflammation reaction involve signaling molecules, inflammatory cells, adhesion molecules and transcriptional regulators.

Increasing amount of $\mathrm{Ca}^{2+}$, oxygen free radical and ischemia itself can activate astrocytes and 
microglia to produce proinflammatory cytokines like interleukin-1 (1L-1), tumor necrosis factor1 (TNF- $\alpha$ ) and interleukin-1 $\beta$ (1L-1 $\beta)$, as well as neuroprotective factors, such as erythropoietin, TGFb1, and metallothionein-2 [16]. Most of these cytokines can induce the production of some adhesion molecules such as selectins ( $P$ selectin, E-selectin), immunoglobulin superfamily (intercellular adhesion molecule-1, vascular endothelial adhesion molecule-1) and integrins. Meanwhile interleukin-8 (1L-8), monocyte adhesion protein chemistry -1 (MCP1) and other chemokines play an important role in the migration of inflammatory cells. With the help of matrix metalloproteinase (MMP), the extracellular matrix is broken down, and inflammatory cells infiltrate the brain parenchyma. 4-6 h after ischemia onset, circulating leukocytes reach the penumbra. Neutrophils are thought to be the first leukocyte subtypes involved in inflammation [17].

\section{Blood-brain barrier (BBB) dysfunction}

Blood-brain barrier (BBB) disruption in acute ischemic stroke varies considerably from 15 to $66 \%$ [18]. Free reactive radicals and inflammation are major reasons that contribute to the damage of the BBB in acute ischemia and reperfusion injury. As important proteases in brain tissue, MMPs and serine proteases are essential in the breakdown of the extracellular matrix around cerebral blood vessels and neurons, and their action leads to the destruction of BBB, brain edema, hemorrhage, and cell death. So, MMPs are thought to be direct factors leading to BBB damage [19]. In ischemic stroke, besides pro-inflammation reaction, free radicals could also affect the activities of MMPs both directly and indirectly.

BBB damage is reported to be biphasic in ischemic stroke [20]. 2 hours after the onset of ischemia, BBB gets a transient opening, which may results from oxidative stress that trigger activation of MMP-9[21] and MMP-2 [22]. This initial opening is followed 1 to 2 days later by a second, more severe opening which is more complicated and last for several days [18,22].

\section{Apoptosis}

There are two forms of cell death, necrosis and apoptosis. In ischemic injury, many brain cells undergo apoptosis, which in contrast to necrosis, is a relatively orderly process that allows cells to die with minimal damage and disruption to neighboring cells [23]. In this way, there is little inflammation or release of genetic material [2,24] and they are potentially recoverable for some time after the onset of stroke.

Caspase-dependent mechanism is important for activation of apoptosis. It includes the intrinsic pathway, initiated by release of cytochrome $\mathrm{C}$ from mitochondria and resulted in activating caspase-3; and the extrinsic pathway, triggered by activation of cell surface death receptors and resulted in activating caspase-8[25]. Additionally, Caspaseindependent mechanism also plays a vital significant role in apoptosis through PARP/AIF pathway $[25,26]$. This is a complex program that received much attention in recent years.

\section{BIOMARKERS IN ACUTE ISCHEMIC STROKE}

In ischemic stroke, ideal biomarkers should exhibit characteristics that include sufficient specificity and sensitivity, early and stable release shortly after infarction, predictable clearance, potential for risk assessment and guidance of therapies, and the ability to be quantitatively and rapidly measured by costeffective methodologies [3,27].Many of the novel biomarkers of cerebral injury are related to the pathophysiology reviewed above, and in clinical scenarios, they may have applications in stroke prediction, diagnosis, assessment, prognosis or treatment.

\section{Coagulation/thrombosis biomarkers}

In most cases, the cause of acute ischemic stroke is atherothrombosis of large cervical or intracranial arteries, or embolism from the heart or cerebropetal arteries [28]. In this way, molecules involved in coagulation or thrombosis are associated with ischemic stroke, including fibrinogen, D-dimer and von Willebrand factor (vWF), which are most reported in recent years.

In terms of risk prediction value, fibrinogen was reported both by Fibrinogen Studies Collaboration that plasma fibrinogen level was significantly associated with coronary heart disease (CHD), stroke, and other causes of vascular and nonvascular mortality [29], and by community-based study in Taiwan that a $72 \%$ increase (hazard ratio, $1.72 ; 1.02$ to 2.90 ) in ischemic stroke risk was observed for individuals with fibrinogen $\geq 8.79 \mu \mathrm{mol} / \mathrm{L}$ compared with those $<7.03 \mu \mathrm{mol} / \mathrm{L}$, suggested fibrinogen is independently predicted future ischemic risk [30]. Also, D-dimer and vWF are reported to be associated with increased risk of stroke in older men., and these associations 
were independent of inflammation, especially for D-dimer, it is a significant predictor of stroke in hypertensive men [31].

As a novel biomarker for diagnosing stroke, VWF can present a high sensitivity and specificity when combined with other markers. Lynch et al. [32] analyzed twenty-six biomarkers with relation to the ischemic cascade, from which a panel of four (S100B, VWF, MMP9, and VCAM) were able to separate ischemic stroke from controls with $90 \%$ sensitivity and specificity. Similarly, Laskowitz et al [33] reported a panel of five biomarkers (S100B, vWF, MMP9, B-type NGF and MCP-1) can diagnose stroke with $92 \%$ sensitivity and $93 \%$ specificity. D-dimer can be used to distinguish cardioembolic stroke from other subtypes of ischemic stroke [34]. When D-dimer was combined with D-dimer/fibrinogen ratio, CRP and erythrocyte sedimentation, it can separate large vessel from cardioembolic stroke [35]. Additionally, it is reported that plasma D-dimer level on admission is significantly related to infarction volume and functional outcome in cardioembolic stroke in non-valvular atrial fibrillation patients [36].

Furthermore, Hasan et al [37] found that Ddimer and fibrinogen have prognostic value with the results that D-dimer predicted in-hospital death (MD $0.67 \mu \mathrm{gml}^{-1}, 95 \% \mathrm{Cl} 0.35,1.00 ; p=$ 0.0001 ), and high fibrinogen levels were associated with poor outcome at 3 months (MD $47.90 \mu^{-1} \mathrm{gml}^{-1}, 95 \% \mathrm{Cl} 14.88,80.93 ; p=0.004$ ) following ischemic stroke.

\section{Biomarkers in oxidative stress}

Since direct measurement of reactive free radical (ROS) in the brain is difficult in humans because of their transient nature and limitation of measurements, endogenous antioxidants as well as several biological substances whose chemical structure has been modified by free radicals have been investigated as potential indirect biomarkers in oxidative stress.

\section{Endogenous antioxidants}

Endogenous antioxidants involve enzymatic (CAT, GPX and SOD) and non-enzymatic antioxidants (retinol, ascorbic acid, uric acid, $\alpha-$ tocopherol and carotenoid), all of which consists of the cellular protective antiradical mechanism.

Antioxidants catalase (CAT) and glutathione peroxidase (GPX) can dispose $\mathrm{H}_{2} \mathrm{O}_{2}$ in a safe way to protect neural cells from oxidative stress. Clinical researches showed that CAT and GPX activity were significantly higher in ischemic patients compared to the controls $[38,39]$, and CAT can be considered as adequate marker for positive outcome [39]. However, others found GPX activity to be significantly lower in stroke patients compared with controls $[40,41]$. This debate may result from the degree of damage by ROS, since antioxidant enzymes might be induced by oxidative stress (and therefore their activity /levels may increase) or else consumed (thus decreasing their activity and levels) [42].

SOD, the most studied antioxidant enzyme in stroke, whose changes of activity/concentration in blood were also strongly disputed. Studies have found the patients' SOD activity in plasma $[39,40]$, serum [43] and red blood cells [41] to be significantly lower than the control group, while others found a contrary result of SOD activity in red blood cells [44]. Similarly, blood concentration of SOD in stroke patients is controversial. This debate may because of the three different isoforms of superoxide dismutase (CuZnSOD, MnSOD and EC-SOD), and the different analysis methods [40]. Most studies indicate that SOD concentration and activity has a significant correlation with neurological deficit and infarct size.

Stroke patients have been found to have lower levels of retinol, ascorbic acid, uric acid, atocopherol and carotenoids $[45,46]$, but many studies have demonstrated some inconsistent or negative results [47]. While, despite some different result in certain non-enzymatic antioxidants, the total antioxidant capacity was immediately reduced in acute ischemic stroke $[48,49]$. And some of them have been shown to have prognosticating value $[48,49]$.

\section{Biomarkers of oxidative products}

ROS can damage lipids, DNA and proteins. Many metabolites produced during these processes can be measured in the serum.

\section{Biomarkers of lipid peroxidation}

The brain cellular membrane lipids are very rich in polyunsaturated fatty acid side chains, which are highly prone to free radical attack resulting in lipid peroxidation that include biomarkers such as malondialdehyde (MDA), thiobarbituric acid-reactive substances (TBARs), lipid peroxides $(\mathrm{ROOH})$ and F2-isoprostanes(F2IPs). 
Plasma levels of MDA, TBARs and lipid peroxides $(\mathrm{ROOH})$ are commonly used biomarkers of oxidative stress. Several studies demonstrated that MDA and TBARs levels are higher in cerebral ischemia patients than in controls, and they are correlated with infarct size, clinical stroke severity, and patient's outcome [38,50-54]. However, both MDA and TBARs lack specificity for measurement of lipid peroxidation, because MDA can not only come from lipid peroxidaion products, but also from degradation of endoperoxides [42], and what is more, when react with TBA, other molecules can degradated MDA which increase the amount of MDA to react with TBA [55].

F2IPs are prostaglandin-like products of noncyclooxygenase free radical-induced peroxidation of arachidonic acid, they are thought to be a reliable marker because of its good stability, sensitivityand specificity. They can be measured in plasma and urine [56]. Kelly et al. found that F2IPs plasma levels were increased early in ischemic stroke patients compared to controls [57]. Nevertheless, there are not enough researches about F2IPs.

\section{Biomarkers of DNA oxidation}

8-hydroxy-2'-deoxyguanosine (8-OHdG), as a product of DNA oxidation, has been widely used as an excellent biomarker of oxidative stress [58]. An animal study showed that plasma levels of $8-\mathrm{OHdG}$ were increased and significantly associated with brain content of 8-OHdG [59]. It could be useful to identify patients with high risk of vascular recurrence or vascular death and to identify some particular atherosclerotic plaques characteristics [60]. In recent years, 8-OHdG has appeared to be a promising molecule, there are still more studies needed to determine whether it can be a useful peripheral biomarker of oxidative damage in stroke patients.

\section{Biomarkers of protein oxidation}

There is a lack of studies on biomarkers of protein oxidation in ischemic stroke in humans. However, a study on patients with Alzheimer's disease and vascular dementia has shown that measuring the protein carbonyl and the dityrosine contents of immunoglobulins $\mathrm{G}(\mathrm{IgG})$ can be feasible not only for its increase compared to controls [61], but also for its sensitivity to dietary antioxidant supplementation [62] and a relatively long half-life of 15 days which making IgG a good short-term marker of oxidative stress [42].

\section{Biomarkers of inflammation}

Compared to controls, serum levels of IL-1 $1 \beta$, IL6 , IL-8, IL-17, TGF- $\beta$, ICAM-1, VCAM-1, Eselectin, L-selectin, P-selectin, TNF- $\alpha$, and MCP-1 has shown elevation [63-67]. When compared to other neurological diseases, serum level of IL-6, TNF- $\alpha$, VCAM-1, BDNF, IL-1 $\beta$, ICAM-1and MMP-2/9 in patients presenting with ischemic stroke were found significantly different and many of them are correlated with neurological deficit and infarct size, such as TNF- $\alpha$, ICAM-1, BDNF and MMP-2/9 [67]. In contrast to the findings from other groups $[68,69]$, Sotgiu et al found that IL-6 serum level showed a significant inverse correlation with both final neurological impairment and infarct size suggesting that IL-6 is associated with neuroprotection rather than neurotoxicity in patients with ischemic brain injury [67].

TNF- $\alpha$ is a major cytokine with a myriad of effects. In an inflammatory reaction, It can be expressed by endothelial cells, microglia and astrocytes, and can induce the expression of other molecules. Hosomi et al [70] proved that during an ischemia, TNF- $\alpha$ can inhibit the production of MMPs and reduce brain edema. While, on the contrary, others thought that TNF- $\alpha$ activated production of MMPs and increases the inflammatory injury [71]. Such different results suggest a complex role of TNF$\alpha$ in inflammatory mechanisms.

As an important indicator of inflammation, Creactive protein (CRP) has been studied extensively. It is an acute phase reactant mainly produced in liver and rapidly upregulated by inflammatory cytokines. Increased levels of high-sensitivity C-reactive protein (hsCRP) levels have been observed in ischemic stroke patients [72]. In ischemic stroke, CRP level are correlated with infarct volume and neurological deficit, and has potential prognostic value for poor outcome [73].

\section{Central nervous system (CNS) tissue injury biomarkers}

Ischemic brain injury always cause CNS damage, leading to a release of neurons or glia specific biomarkers such as acidic calciumbinding protein $(S 100 \beta)$, glial fibrillary acidic protein (GFAP), myelin basic protein (MBP), neuron-specific enolase (NSE).

Previous studies have agreed that NSE and $S 100 \beta$ were thought to be of great value for the 
severity of cerebral infarction and prognosis estimation in ischemic stroke. Under normal circumstances, content of NSE and $S 100 \beta$ is very low, while when there is an ischemic injury, they are released into the cerebrospinal fluid (CSF) and the blood through the damaged BBB, resulting in an increased levels of NSE and S100 $\beta$ [74]. They are closely correlated with severity, infarct size and outcome $[75,76]$.

GFAP is a structural protein that is only present in astrocytes, and to a lesser degree, in ependymal cells of the brain. It is released when cells are disintegrated and the cytoskeletons are degraded and its overexpression is specific for neurological injury [77]. MBP is a hydrophilic protein important for the correct structure of myelin sheaths and accounting for about $30 \%$ of myelin proteins. When the CNS and myelin are damaged, GFAP and MBP can be released into CSF and blood, and their levels are correlated to the degree of injury. They can used to be a potential biomarker of CNS injury.

\section{Miscellaneous biomarkers}

Nucleoside diphosphate kinase A (NDKA) and Parkinson's disease protein 7 (PARK7) are recently discovered biomarkers that are closely related to ischemic stroke, though their mechanism in stroke is not clear. Concentrations of NDKA and PARK7 were both increased within $3 \mathrm{~h}$ of stroke, with sensitivity of $54-91 \%$ for PARK7 and $70-90 \%$ for NDKA and specificity of $80-97 \%$ for PARK7 and $90-$ $97 \%$ for NDKA suggesting that they can be reliable biomarkers for the early diagnosis of stroke [78]. When combined GFAP、NDKA and PARK7, higher sensitivity and specificity were observed [79].

\section{CONCLUSION}

The pathophysiological processes following acute ischemic stroke are extremely complex. Understanding of pathophysiology can help improve current clinical conditions of stroke, including diagnosis, assessment, prognosis and therapy. Meanwhile, biomarkers reflecting relevant events in the ischemic cascade would also be of great use.

Though a number of blood based biomarkers of ischemic stroke have been observed, there is much difficulty in successfully translating this advancement to remarkable application in clinical practice. Many of them are related to the underlying pathophysiology of ischemic stroke. The pathogenesis of stroke is complex, involving multiple mechanisms, in this way, the detection of stroke by use of markers may require multiple markers to capture simultaneously all processes underlying the ongoing ischemic event [80]. Clearly there is much work needed before promising biomarker candidates can be introduced into the clinical practice.

\section{ACKNOWLEDGEMENT}

This work was supported, in part, by Innovation Team Development Program of Beijing University of Chinese Medicine (nos. 2011CXTD-13 and JYBZZ-JS021).

\section{REFERENCES}

1. Roger VL, Go AS, Lloyd-Jones DM, Benjamin EJ, Berry $J D$, Borden WB, Bravata DM, Dai S, Ford ES, Fox CS, et al. American Heart Association Statistics Committee, Stroke Statistics Subcommittee. Heart disease and stroke statistics--2012 update: a report from the American Heart Association. Circulation 2012; 125: e2-220.

2. Morales-Vidal S. Stroke pathophysiology. Stroke 2013; 6-20.

3. Saenger AK, Christenson RH. Stroke biomarkers: progress and challenges for diagnosis, prognosis, differentiation, and treatment. Clinical chemistry 2010:56(1): 21-33.

4. Mishra LD. Cerebral blood flow and anaesthesia. Indian J. Anaesth 2002; 46(2), 87-95.

5. Zuming Luo; Xinsheng Ding. Ischemic cerebral vascular disease. Beijing: People's Medical Publishing House; 2012.(Chinese)

6. Mui K, Yoo AJ, Verduzco L, Copen WA, Hirsch JA, González RG, Schaefer PW. Cerebral blood flow thresholds for tissue infarction in patients with acute ischemic stroke treated with intra-arterial revascularization therapy depend on timing of reperfusion. Am. J. Neuroradiol 2011; 32(5): 846851.

7. Mehta SL, Manhas N, Rahubir R. Molecular targets in cerebral ischemia for developing novel therapeutics. Brain Research Reviews 2007; 54: 34-66.

8. Traystamn RJ, Kirsch JR, Koehler RC. Oxygen radical mechanism of brain injury following ischaemia and reperfusion. J Appl Physiol 1991; 71: 1185-1195.

9. Cuzzocrea $S$, Riley $D P$, Caputi $A P$, Salvemini $D$. Antioxidant therapy: a new pharmacological approach in shock, inflammation, and ischemia/reperfusion injury. Pharmacological reviews 2001; 53: 135-159.

10. Allen CL, Bayraktutan U. Oxidative stress and its role in the pathogenesis of ischaemic stroke. International Journal of Stroke 2009; 4: 461-470.

11. Aygul R, Kotan D, Demirbas F, Ulvi H, Deniz O. Plasma oxidants and antioxidants in acute ischaemic stroke. Journal of international medical research 2006; 34(4): 413-418.

12. Patt A, Harken AH, Burton LK, Rodell TC, Piermattei $D$,Schorr WJ,Parker NB, Berger EM,Horesh IR, Terada LS. Xanthine oxidase-derived hydrogen peroxide contributes to ischaemia perfusioninduced oedema in gerbil brain. J Clin Invest 1988; 81: 1556-1562.

13. Beckman JS, Ye YZ, Chen J, Conger KA. The interactions of nitric oxide with oxygen radicals and scavengers in cerebral ischemic injury. Adv Neurol 1996; 71: 339-350.

Trop J Pharm Res, December 2013;12 (6):1102 
14. Choi K, Kim J, Kim GW, Choi C: Oxidative stressinduced necrotic cell death via mitochondiradependent burst of reactive oxygen species. Current Neurovascular Research 2009; 6: 213222.

15. Woodruff TM, Thundyil J, Tang SC, Sobey CG, Taylor SM, Arumugam TV, Pathophysiology, treatment, and animal and cellular models of human ischemic stroke. J Molecular Neurodegeneration 2011; 6: 11

16. Mergenthaler P, Dirnagl U, Meisel A: Pathophysiology of stroke: Lessons from animal models. Metabolic Brain Disease 2004: 19: 151-167.

17. Buck BH, Liebeskind DS, Saver JL, Bang OY, Yun SW, Starkman S, Ali LK, Kim D, Villablanca JP, Salamon N,et al. Early neutrophilia is associated with volume of ischemic tissue in acute stroke. Stroke 2008; 39(2): 355-360.

18. Brouns R, De Deyn PP. The complexity of neurobiological processes in acute ischemic stroke. Clinical neurology and neurosurgery 2009; 111(6): 483-495.

19. Jian LK, Rosenberg GA. Matrix metalloproteinases and free radicals in cerebral ischemia. Free Radical Biology and Medicine 2005; 39(1): 71-80.

20. Huang ZG, Xue D, Preston E, Karbalai H, Buchan AM. Biphasic opening of the blood-brain barrier following transient focal ischemia: effects of hypothermia. Can J Neurol Sci 1999; 26: 298304.

21. Wagner S,Nagel S, Kluge B, Schwab S, Heiland S, Koziol J, Gardner H, Hacke W. Topographically graded postischemic presence ofmetalloproteinases is inhibited by hypothermia. Brain Res 2003; 984: 63-75.

22. Yang $Y$, Estrada $E Y$, Thompson JF, Liu W, Rosenberg GA. Matrix metalloproteinase-mediated disruption of tight junction proteins in cerebral vessels is reversed by synthetic matrix metalloproteinase inhibitor in focal ischemia in rat. Journal of Cerebral Blood Flow \& Metabolism 2006; 27(4): 697-709.

23. Broughton BRS, Reutens DC, Sobey CG. Apoptotic Mechanisms After Cerebral Ischemia. Stroke 2009, 40: E331-E9.

24. Namura S, Zhu J, Fink $K$, Endres $M$, Srinivasan A, Tomaselli KJ, Yuan J, Moskowitz MA. Activation and cleavage of caspase-3 in apoptosis induced by experimental cerebral ischemia. J Neurosci 1998; 18: 3659-3668.

25. Broughton BR, Reutens DC, Sobey CG. Apoptotic mechanisms after cerebral ischemia. Stroke 2009; 40(5): E331-9.

26. Cho BB, Toledo-Pereyra LH. Caspase-independent programmed cell death following ischemic stroke. J Invest Surg 2008; 21: 141-147.

27. Rothstein L, Jickling GC. Ischemic stroke biomarkers in blood. Biomarkers 2013; 7(1): 169-186.

28. Hossmann KA. Viability thresholds and the penumbra of focal ischemia. Annals of neurology 1994; 36(4): 557-565.

29. Collaboration FS. Plasma fibrinogen level and the risk of major cardiovascular diseases and nonvascular mortality. JAMA: the journal of the American Medical Association 2005; 294(14): 1799-1809.

30. Chuang SY, Bai CH, Chen WH, Lien LM, Pan WH. Fibrinogen Independently Predicts the Development of Ischemic Stroke in a Taiwanese Population CVDFACTS Study. Stroke 2009; 40(5): 1578-1584.

31. Wannamethee SG, Whincup $P H$, Lennon L, Rumley $A$, Lowe GD. Fibrin D-Dimer, Tissue-Type Plasminogen Activator, von Willebrand Factor, and Risk of Incident Stroke in Older Men. Stroke 2012; 43(5): 1206-1211
32. Lynch JR, Blessing $R$, White WD, Grocott HP, Newman MF, Laskowitz DT. Novel diagnostic test for acute stroke. Stroke 2004; 35(1): 57-63.

33. Laskowitz DT, Blessing R, Floyd J, White WD, Lynch JR. Panel of biomarkers predicts stroke. Annals of the New York Academy of Sciences 2005; 1053(1): 30-30.

34. Ageno W, Finazzi S, Steidl L, Biotti MG, Mera V, Melzid'Eril G, Venco A. Plasma measurement of $D$ dimer levels for the early diagnosis of ischemic stroke subtypes. Archives of internal medicine 2002; 162(22): 2589.

35. Alvarez-Perez F J, Castelo-Branco M, Alvarez-Sabin J. Usefulness of measurement of fibrinogen, $D$ dimer, $D$-dimer/fibrinogen ratio, $C$ reactive protein and erythrocyte sedimentation rate to assess the pathophysiology and mechanism of ischaemic stroke. Journal of Neurology, Neurosurgery \& Psychiatry 2011; 82(9): 986-992.

36. Matsumoto M, Sakaguchi M, Okazaki S, Furukado S. Tagaya M. Etani H. Shimazu T. Yoshimine $T$. Mochizuki H. Kitagawa K. Relationship between Plasma D-Dimer Level and Cerebral Infarction Volume in Patients with Nonvalvular Atrial Fibrillation. Cerebrovascular Diseases 2013; 35(1): 64-72.

37. Hasan N, McColgan P, Bentley P, Edwards RJ, Sharma $P$. Towards the identification of blood biomarkers for acute stroke in humans: a comprehensive systematic review. British journal of clinical pharmacology 2012; 74(2): 230-240.

38. Alexandrova $M$, Bochev $P$, Markova $V$, Bechev $B$, Popova M, Danovska M, Simenonva V. Dynamics of free radical processes in acute ischemic stroke: influence on neurological status and outcome. Journal of Clinical Neuroscience 2004; 11(5): 501506.

39. Sapojnikova N, Asatiani N, Kartvelishvili T, Kalandadze I,Tsiskaridze A. Plasma Antioxidant Activity as a Marker for a Favourable Outcome in Acute Ischemic Stroke. 2012.

40. Aygul R, Kotan D, Demirbas F, Ulvi H, Deniz O. Plasma oxidants and antioxidants in acute ischaemic stroke. Journal of international medical research 2006; 34(4): 413-418.

41. Demirkaya S, Topcuoglu MA, Aydin A, Ulas UH, Isimer Al, Vural O. Malondialdehyde, glutathione peroxidase and superoxide dismutase in peripheral blood erythrocytes of patients with acute cerebral ischemia. European Journal of Neurology 2001; 8(1): 43-51.

42. Cherubini A, Ruggiero C, Polidori MC, Mecoccia P. Potential markers of oxidative stress in stroke. Free Radical Biology and Medicine 2005; 39(7): 841-852.

43. Spranger M, Krempien S, Schwab S, Donneberg S, Hacke W. Superoxide dismutase activity in serum of patients with acute cerebral ischemic injury correlation with clinical course and infarct size. Stroke 1997; 28(12):2425-2428.

44. Kocatürk PA, Akbostanci MC, Issikay C, Ocal A, Tuncel $D$, Kavas GO, Mutluer N. Antioxidant status in cerebrovascular accident. Biological Trace Element Research 2001; 80(2): 115-124.

45. El Kossi MMH, Zakhary MM. Oxidative stress in the context of acute cerebrovascular stroke. Stroke 2000; 31(8): 1889-1892.

46. Chang CW, Lai MC, Cheng TJ, Lau MT, Hu ML Plasma levels of antioxidant vitamins, selenium, total sulfhydryl groups and oxidative products in ischemic-stroke patients as compared to matched controls in Taiwan. Free radical research 1998; 28(1): 15-24.

47. Gariballa SE, Hutchin TP, Sinclair AJ. Antioxidant capacity after acute ischaemic stroke. Qjm 2002; 
95(10): 685-690

48. Cherubini A, Polidori MC, Bregnocchi M, Pezzuto S; Cecchetti $R$, Ingegni $T$, Angelo di lorio, Senin $U$, Mecocci $P$. Antioxidant profile and early outcome in stroke patients. Stroke 2000; 31(10): 22952300.

49. Weir CJ, Muir SW, Walters MR, Lees KR. Serum urate as an independent predictor of poor outcome and future vascular events after acute stroke. Stroke 2003; 34(8): 1951-1956.

50. Sharpe PC, Mulholland C, Trinick T. Ascorbate and malondialdehyde in stroke patients. Irish journal of medical science 1994; 163(11): 488-490.

51. Bolokadze N, Lobjanidze I, Momtselidze N, Solomonia $R$, Shakarishvili $R$, Mchedlishvili $G$. Blood rheological properties and lipid peroxidation in cerebral and systemic circulation of neurocritical patients. Clinical hemorheology and microcirculation 2004; 30(2): 99-105.

52. Skochii PH, Korol HM, Tymochko MF. The characteristics of lipid peroxidation in patients with an acute disorder of the cerebral circulation]. Likars' ka sprava/Ministerstvo okhorony zdorov'ia Ukraïny 1992; (6): 94.

53. Polidori MC, Frei B, Cherubini A, Nelles G, Rordorf G, Jr JFK, Schwamm L, Mecocci P, Koroshetz W, Beal MF. Increased plasma levels of lipid hydroperoxides in patients with ischemic stroke. Free Radical Biology and Medicine 1998; 25(4): 561-567.

54. El Kossi MMH, Zakhary MM. Oxidative stress in the context of acute cerebrovascular stroke. Stroke 2000; 31(8): 1889-1892.

55. Halliwell $B$, Chirico S. Lipid peroxidation: its mechanism, measurement, and significance [J]. The American journal of clinical nutrition 1993; 57(5): 715S-724S

56. Morrow JD. Quantification of isoprostanes as indices of oxidant stress and the risk of atherosclerosis in humans. Arteriosclerosis, thrombosis, and vascular biology 2005; 25(2): 279-286.

57. Kelly PJ, Morrow JD, Ning MM, Koroshetz W, Lo EH, Terry E, Milne GL, Hubbard J, Lee H, Stevenson $E$, et al. Oxidative Stress and Matrix Metalloproteinase-9 in Acute Ischemic Stroke The Biomarker Evaluation for Antioxidant Therapies in Stroke (BEAT-Stroke) Study. Stroke 2008; 39(1): 100-104.

58. Liu $H$, Uno $M$, Kitazato KT, Suzue A, Manabe S, Yamasaki $H$, Shono $M$, Nagahiro S. Peripheral oxidative biomarkers constitute a valuable indicator of the severity of oxidative brain damage in acute cerebral infarction. Brain Research 2004; 1025(1): 43-50.

59. Nagayama T, Lan J, Henshall DC, Chen D, O'Horo C, Simon RP, Chen J. Induction of oxidative DNA damage in the peri - infarct region after permanent focal cerebral ischemia. Journal of neurochemistry 2000; 75(4): 1716-1728.

60. Brea $D$, Roquer J, Serena J, Segura T, Castillo J. Oxidative stress markers are associated to vascular recurrence in non-cardioembolic stroke patients non-treated with statins. BMC neurology 2012; 12(1): 65.

61. Polidori MC, Mattioli P, Aldred S, Cecchetti R, Stahl W, Griffiths $H$, Senin $U$, Sies $H$, Mecocci P. Plasma antioxidant status, immunoglobulin $g$ oxidation and lipid peroxidation in demented patients: relevance to Alzheimer disease and vascular dementia. Dementia and geriatric cognitive disorders 2004; 18(3-4): 265-270.

62. Carty JL, Bevan R, Waller H, Mistry N, Cooke M, Lunec $J$, Griffiths HR. The effects of vitamin $C$ supplementation on protein oxidation in healthy volunteers. Biochemical and biophysical research communications 2000; 273(2): 729-735.

63. Kostulas $N$, Pelidou SH, Kivisäkk $P$, Kostulas V, Link $H$. Increased IL-1 $\beta, I L-8$, and IL-17 mRNA expression in blood mononuclear cells observed in a prospective ischemic stroke study. Stroke 1999; 30(10): 2174-2179.

64. Beamer NB, Coull BM, Clark WM, Hazel JS, Silberger JR. Interleukin-6 and interleukin-1 receptor antagonist in acute stroke. Ann. Neurol 1995; 37(6): 800-805.

65. Kim JS, Yoon SS, Kim YH, Ryu JS. Serial measurement of interleukin-6, transforming growth factor, and S-100 protein in patients with acute stroke. Stroke 1996; 27(9):1553-1557.

66. Montaner J, Alvarez-Sabín J, Barberá G, Anglés A, Molina $C$, Abilleira $S$, Arenillas $J$, Chacón $P$, Monasterio J. Correlation between the expression of proinflammatory cytokines and matrix metalloproteinases in the acute phase of an ischemic stroke. Rev. Neurol 2001; 33(2): 115118.

67. Sotgiu S, Zanda B, Marchetti B, Fois ML, Arru G, Pes GM, Salaris FS, Arru A, Pirisi A, Rosati G. Inflammatory biomarkers in blood of patients with acute brain ischemia. Eur. J. Neurol 2006; 13(5). 505-513.

68. Montaner J, Rovira A, Molina CA, Arenillas JF,Ribó M, Chacón $P$, Monasterio J, Alvarez-Sabín J. Plasmatic level of neuroinflammatory markers predict the extent of diffusion-weighted image lesions in hyperacute stroke. Journal of Cerebral Blood Flow \& Metabolism 2003; 23(12): 14031407.

69. Smith CJ, Emsley HCA, Gavin CM, Georgiou RF, Vail A, Barberan EM, del Zoppo GJ, Hallenbeck JM, Rothwell NJ, Hopkins SJ. Peak plasma interleukin6 and other peripheral markers of inflammation in the first week of ischaemic stroke correlate with brain infarct volume, stroke severity and long-term outcome. BMC neurology 2004; 4(1): 2.

70. Hosomi N, Ban CR, Naya T, Takahashi T, Guo P, Song $X R$, Kohno $M$. Tumor necrosis factor- $\alpha$ neutralization reduced cerebral edema through inhibition of matrix metalloproteinase production after transient focal cerebral ischemia. Journal of Cerebral Blood Flow \& Metabolism 2005; 25(8): 959-967.

71. Hallenbeck JM. The many faces of tumor necrosis factor in stroke. Nature medicine 2002; 8(12): 1363-1368.

72. Winbeck K, Poppert H, Etgen T, Conrad B, Sander D. Prognostic relevance of early serial $C$-reactive protein measurements after first ischemic stroke. Stroke 2002; 33(10): 2459-2464.

73. Rajeshwar K, Kaul S, Al-Hazzani A, Babu MS, Balakrishna N, Sharma V, Jyothy A, Munshi A. Creactive protein and nitric oxide levels in ischemic stroke and its subtypes: correlation with clinical outcome. Inflammation 2012; 35(3): 978-984.

74. van Munster BC, Korse CM, de Rooij SE, Bonfrer JM, Zwinderman AH, Korevaar JC. Markers of cerebral damage during delirium in elderly patients with hip fracture. BMC neurology 2009; 9(1): 21.

75. Tanaka Y, Marumo T, Omura T, Yoshida S. Relationship between cerebrospinal and peripheral $S 100 B$ levels after focal cerebral ischemia in rats. Neuroscience letters 2008; 436(1): 40-43.

76. Bharosay A, Bharosay VV, Varma M, Saxena K, Sodani $A$, Saxena $R$. Correlation of Brain Biomarker Neuron Specific Enolase (NSE) with Degree of Disability and Neurological Worsening in Cerebrovascular Stroke. Indian Journal of Clinical Biochemistry 2012; 27(2): 186-190.

77. Pelinka LE, Kroepfl A, Schmidhammer R, Krenn $M$, Buchinger $W$, Redl $H$, Raabe $A$. Glial fibrillary 
acidic protein in serum after traumatic brain injury and multiple trauma. The Journal of Trauma and Acute Care Surgery 2004; 57(5): 1006-1012.

78. Allard L, Burkhard PR, Lescuyer P, Burgess JA, Walter N. Hochstrasser DF, Sanchez JC. PARK7 and nucleoside diphosphate kinase $A$ as plasma markers for the early diagnosis of stroke. Clinical chemistry 2005; 51(11): 2043-2051.

79. Guiping C, Ping L,Ping Y, Hui L,Jianwei L,Wei Z.
Clinical application serum GFAP. NDKA and PARK7 in patients with ischemic stroke. Clin J Lab Med. 2011; 34(9): 779-784. (Chinese)

80. Allard L, Burkhard PR, Lescuyer P, Burgess JA, Walter $N$, Hochhstrasser DF, Sanchez JC. PARK7 and nucleoside diphosphate kinase $A$ as plasma markers for the early diagnosis of stroke. Clinical chemistry 2005; 51(11): 2043-2051. 